\title{
Malignant mesothelioma due to environmental exposure to erionite: follow-up of a Turkish emigrant cohort
}

\author{
M. Metintas*, G. Hillerdal ${ }^{+}$, S. Metintas
}

\begin{abstract}
Malignant mesothelioma due to environmental exposure to erionite: follow-up of a Turkish emigrant cohort. M. Metintas, G. Hillerdal, S. Metintas. CERS Journals Ltd 1999.

ABSTRACT: The incidence of malignant mesothelioma is extremely high in some Turkish villages where there is a low-level environmental exposure to erionite, a fibrous zeolite. The best known example is the village of Karain. However, since epidemiological studies are difficult to perform in Turkey, the incidence and the doseresponse curve have not been thoroughly examined.

A small cohort of immigrants from Karain who have lived in Sweden for many years were studied. Exposure data, i.e. the time residing in Karain, and hospital records including pathological diagnosis, were recorded.

The cohort consisted of 162 people. During the observation time, 18 deaths occurred, $14(78 \%)$ of which were due to malignant pleural mesothelioma. In addition, there were five patients with mesothelioma who were still alive, one of whom had a peritoneal mesothelioma.

Thus, the risk of mesothelioma is 135-times and 1,336-times greater in males and females, respectively, than for the same sex and age groups in Sweden. The risk increased with duration of residence.

Eur Respir J 1999; 13: 523-526.
\end{abstract}

Depts of *Chest Diseases and ${ }^{*}$ Public Health, Medical School of Osmangazi University, Eskisehir, Turkey. ${ }^{+}$Dept of Lung Medicine, Karolinska Hospital, Stockholm, Sweden.

Correspondence: M. Metintas, Ömeraga mahallesi, Adsiz Sokak No:11, 26220 Eskisehir, Turkey, Fax: 902222394714

Keywords: Environmental exposure epidemiology

erionite

immigrants

mesothelioma

Received: April 241998

Accepted after revision December 81998

Malignant pleural mesothelioma is a frequent cause of death in three villages of the Cappadocian region of central Anatolia in Turkey: Sarihidir, Tuzköy, and Karain. A naturally fibrous zeolite called erionite can be found in the bedrock of these three villages, causing a low-level environmental exposure to the villagers. The health risks of erionite have been well demonstrated in epidemiological and experimental studies [1-6]. The main result of exposure is a highly increased risk of malignant pleural mesothelioma. In the village of Karain, the incidence of this otherwise very rare tumour is extremely high, and this disease is in fact the most common cause of death there.

Migration from these Turkish villages to cities in Turkey and to other European countries has been fairly extensive, mainly for economic reasons, but in the case of a village like Karain also because of the health risks of erionite. Hence, since 1965, 168 villagers from Karain have emigrated to Stockholm and have resided there. In this small cohort, two studies were performed in 1980 and 1986. A high rate of mesothelioma ( 7 cases) and some radiological findings probably related to erionite exposure were demonstrated $[7,8]$. This cohort, with a stable population and good health surveillance, is suitable for obtaining the incidence of malignant pleural mesothelioma in persons environmentally exposed to erionite.

In the present study, the mesothelioma rate in the cohort up to 1997 is reported.

\section{Material and methods}

\section{Karain cohort}

Karain is a village of Ürgüp in the Cappadocian area of Turkey. In 1950 it was estimated that it had a population of about 2,000 [1], but according to the latest census and to personal communications from the villagers, the approximate population today is only $\sim 250$ persons.
The first Karainers arrived in Stockholm in 1965 to be followed by others. They live near each other and form a rather homogenous group, but are otherwise well integrated into Swedish society and have in general been economically successful. They have formed an association called "The Cultural Association of Turkish-Swedish" (CATS), which now has 450 members. However, many of these have been born in Sweden, and only 168 people originate from Karain having lived there in their childhood and youth. Six of these 168 have returned to Turkey, therefore the Karain-born cohort residing in Stockholm is 162 people in total ( 87 males and 75 females).

The CATS registers contain the member's name, age, length of time spent in Karain, the date of coming to Stockholm, occupation, the date and cause of death, and also marriage status and other details. These data were used and completed with death and hospitals records including pathological findings, and further checked by the local cancer registry to trace all causes of death and verify any diagnosis of mesothelioma.

\section{Calculations}

Every year of residence in Sweden from 1965-1997 by a member of the Karain-born cohort was counted as a person-yr. The year of diagnosis of mesothelioma or year of death was counted as half a year; if the person survived for $\geq 1$ yrs after diagnosis of mesothelioma, these years were disregarded.

For every year, the number of observation-yrs in each 5 -yr age group was calculated. The number of observationyrs in each 5-yr age group was multiplied with the expected incidence for malignant pleural mesothelioma for this particular 5-yr age group of females and males in the given year. This latter figure was taken from the Official Cancer Registry of Sweden, which has calculated these incidences for each year. Since the latest available year of 
the Registry was 1994, the figures for this year were used for 1995,1996 , and 1997. The resulting figures of expected malignant pleural mesothelioma for each year and age group were added, giving the total number of expected cases in the cohort. This method has been used in other similar studies [9, 10].

The mesothelioma standardized incidence ratio (mSIR) was calculated by dividing the observed number of cases by the expected number of cases. The $95 \%$ confidence intervals $(\mathrm{CI})$ of the mSIRs were calculated to assess statistical significance as follows. The standard error of the natural logarithm of the mSIR was approximated by the inverse of the square root of the observed number of cases. The $95 \%$ confidence limits of SIR were calculated as the natural logarithm of SIR (ln SIR) adding percentage standard error and multiplying by 1.96. After exponentiation, the exact $95 \%$ confidence limits suggested that the approximation was satisfactory.

Direct standardized average annual mesothelioma incidence rates (AMIRs), adjusted to the 1970 Swedish standard population, were calculated as follows: age-specific rates (in groups of 5-yr intervals) are computed for the Karain cohort. These rates are applied to the number of persons in the corresponding age group in the standard population (1970 Swedish standard population) and the results are summed. This sum is divided by the total number of persons in the standard population. This standardized rate is divided by the observation-yrs ( $32 \mathrm{yrs})$ and thus, the direct standardized average AMIRs were obtained.

\section{Results}

There were 2,072.5 person-yrs in the male group and 1,638.5 person-yrs in the female. Age, sex and residing time in Karain are shown in table 1 and the age distribution in figure 1 .

Of the 162 patients, 18 have died. Of the deaths, 14 (78\%) were due to malignant pleural mesothelioma. One of the dead patients was strongly suspected to have mesothelioma, although this could not be definitely diagnosed, since the patient returned to Turkey and died there. Three of these patients were reported in the first study [7] and four in the second study [8]. An additional five patients are alive today with mesothelioma, four pleural and one peritoneal. Thus, a total of 18 malignant pleural mesothelioma and one peritoneal mesothelioma have been demonstrated in this small group between 1965 and 1997.

Of the 18 mesothelioma patients, 10 were female and 8 male, giving a male:female ratio of 0.8 . The mean \pm SD age of disease appearance was $53 \pm 13$ yrs (range: $37-71$ ) for males and 48 \pm 11 yrs (range: 28-67) for females. These periods also correspond to the time interval from first

Table 1. - Age, sex and exposure duration characteristics in the Karain-born cohort

\begin{tabular}{lcc}
\hline & Male & Female \\
& $\mathrm{n}=87$ & $\mathrm{n}=75$ \\
\hline Age yrs & $44.5 \pm 12.5$ & $44.3 \pm 12.9$ \\
& $(23-77)$ & $(24-74)$ \\
Duration of living in Karain yrs & $20.8 \pm 10.6$ & $21.4 \pm 13.3$ \\
& $(1-60)$ & $(1-58)$ \\
\hline
\end{tabular}

Data are presented as mean \pm SD with ranges in parentheses.

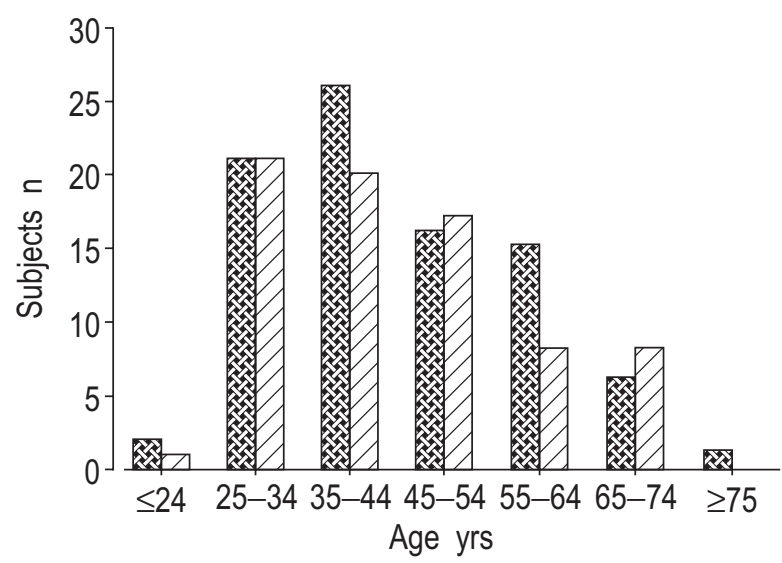

Fig. 1. - Age distribution of the 162 subjects from the Karain-born cohort. : males; $\mathbb{Z}$ : females.

exposure to erionite, i.e. the latency time. The difference in latency time between male and female cases was not significant $(p>0.05)$. Six of the malignant pleural mesothelioma cases $(33 \%)$ were in the 35-44 yrs age group, two patients were aged $<40 \mathrm{yrs}$, and only one patient was $>70$ yrs.

The average adjusted AMIRs per 100,000 people in this study group are shown in table 2. During the observation period, 1965-1997, only 0.030 cases of malignant pleural mesothelioma were expected in the cohort among the males and 0.005 among the females. The observed numbers were clearly much higher (table 3 ).

The average duration of exposure to erionite (i.e. the time spent living in Karain) was $27 \pm 10$ yrs for males with mesothelioma and $32 \pm 8$ for females. There was no significant difference between the males and the females in this regard, nor was there any difference between those with mesothelioma and the rest of the cohort. However, it could be seen that none of the 21 persons who had lived $<10 \mathrm{yrs}$ in the village had developed the tumour (fig. 2).

\section{Discussion}

Erionite is a natural fibrous zeolite, found in certain volcanic tuffs as an environmental contaminant. Erionite is morphologically similar to amphibole asbestos, but its physical and chemical properties are different. The erionite fibre has an hexagonal physical structure and an internal area that is $200 \mathrm{~m}^{2} \cdot \mathrm{g}^{-1}$, about 20-times larger than the internal surface of crocidolite asbestos. Hence, erionite has

Table 2. - Average annual mesothelioma incidence rates (AMIRs) for malignant pleural mesothelioma (per 100,000 population) in the Karain-born cohort

\begin{tabular}{lrccc}
\hline & $\begin{array}{c}\text { Cases } \\
\mathrm{n}\end{array}$ & $\begin{array}{c}\text { Average } \\
\text { AMIR }\end{array}$ & $\begin{array}{c}\text { Ratio to state } \\
\text { (Sweden)* }\end{array}$ & Ratio to world* \\
\hline Male & 8 & 298.1 & 135.5 & 229.3 \\
Female & 10 & 400.9 & 1336.3 & 2004.5 \\
\hline
\end{tabular}

*: the incidences of malignant pleural mesothelioma for Sweden and the whole world were those of 1993. The expected incidence is 2.2 per 100,000 for males and 0.3 for females in Sweden; for the whole world, these figures are 1.3 and 0.2 , respectively [11, 12]. 
Table 3. - Observed and expected rates of malignant pleural mesothelioma in the 162 subjects of the Karainborn cohort

\begin{tabular}{lcccc}
\hline & $\begin{array}{c}\text { Observed } \\
\mathrm{n}\end{array}$ & Expected* & mSIR & $95 \% \mathrm{CI}$ \\
\hline Male & 8 & 0.030 & 264.9 & $132.4-529.5$ \\
Female & 10 & 0.005 & 1992.0 & $1072-3703$ \\
\hline
\end{tabular}

mSIR: mesothelioma standardized incidence ratio; CI: confidence interval. ${ }^{*}$ : data from [12].

the ability to adsorb small molecules and possesses a strong catalytic activity [13]. Environmental exposure to erionite as a cause of mesothelioma has been well documented through the pioneering studies of BARIS et al. [2] in three villages of the Cappadocian region of Turkey. Many other investigations have confirmed the extraordinarily high incidence of mesothelioma in these three villages, and in particular in Karain [14-16]. The villages were built on and into soft volcanic tuff which unfortunately contained erionite fibres as a constituent, albeit in only small amounts. Erionite fibres have been identified in the airborne dust and in the lungs of patients with mesothelioma [2, 17]. Experimental studies of animals and further epidemiological studies confirmed that erionite fibres are very potent carcinogens and in fact more potent than asbestos fibres [1,3-6, 18]. A recent study of the mortality data of the Karain village revealed that of 305 deaths $49 \%$ were due to malignant mesothelioma [1].

In the present study, malignant pleural mesothelioma was by far the most common cause of death in this small, but well-defined group of former Karain villagers. The incidence rates for both sexes are extremely high and higher than those observed in cohorts occupationally exposed to asbestos. For instance, the average annual incidence of mesothelioma in lower Normandy in an asbestos factory was estimated to be 88 per 100,000 , compared with a mean incidence of 19 in ship building and repairs and 122.4 in the workers of textile and friction linings [19]; still less than half of that calculated for the Karain cohort in the present study.

In this small cohort study, 14 of 18 deaths (78\%) were due to malignant pleural mesothelioma. The proportional mortality for villagers still living in Karain has been es-

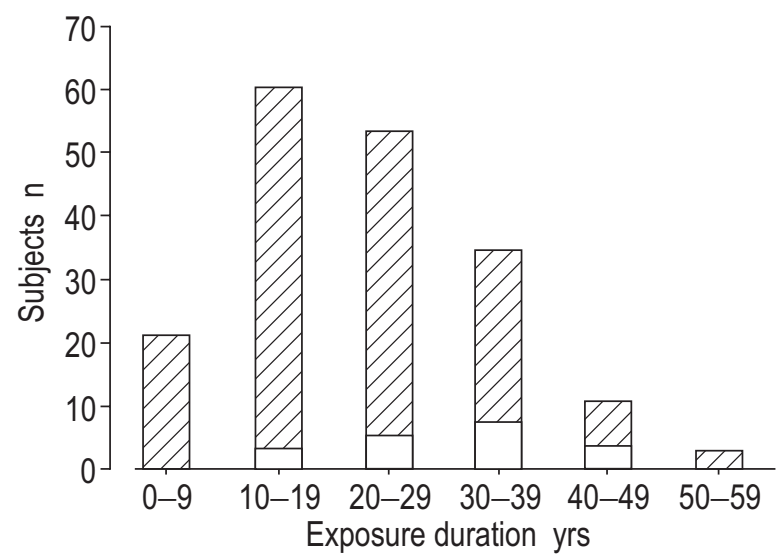

Fig. 2. - Distribution of the durations of erionite exposure in cases with malignant pleural mesothelioma $(\square)$ with respect to all emigrants. $\mathbb{Z}$ : immigrants without mesothelioma. timated to be $49 \%$ [1]. Both of these values are extremely high, but it is believed that the figures in the present cohort more realistically mirror the real risk from environmental exposure to erionite. This is believed to be the case because, firstly, the cohort living in Sweden is more stable, with less migration, and secondly, the diagnoses of mesothelioma were all undertaken in hospital conditions with histopathological confirmation. However, even if the proportional mortality is only about $50 \%$, as suggested by the study at the village [1], this is far more than published figures from workers occupationally exposed to asbestos. In crocidolite miners, the proportional risk was calculated to be $3.9 \%$ [20]. In another study from the same area above, i.e. Wittenoom in western Australia, where there was a heavy contamination of the surroundings of the mine including the village itself, the life-long risk of mesothelioma was calculated to be $6 \%$ for the work force, $1.9 \%$ for the female residents, and $1.1 \%$ for the children [21]; figures very much lower than those seen in Karain. This is despite the fact that the exposure levels (i.e. number of inhaled fibres) were considerably higher in Wittenoom [22].

The environmental exposure level in Wittenoom was estimated to be 1.0 fibres $\cdot \mathrm{cm}^{-3}$ from $1943-1957$ and 0.5 fibres $\cdot \mathrm{cm}^{-3}$ between 1958 and 1966 , when the mine was closed. These values were estimated from environmental measurements, the earliest of which were taken in 1966 [22]. Outdoor samples from Karain gave levels of $0.002-$ 0.01 fibres $\mathrm{cm}^{-3}$ with a mean of 0.006 fibres $\cdot \mathrm{cm}^{-3}$ and $80 \%$ of the fibres being shown to be erionite [2]. The levels of fibres in samples from family caves during cleaning were also low, ranging $0.005-0.31$ fibres $\cdot \mathrm{cm}^{-3}$ before and after sweeping $[2,15]$. Thus, only in rare situations did the fibre levels in Karain come even close to those in Wittenoom, and the average daily background exposures to mineral fibres were probably at least 100-times higher for the Wittenoom inhabitants. Despite this, the mesothelioma risk in Wittenoom is much smaller than in Karain. In a cohort of 4,569 former residents, who lived there at least one month, 27 cases of mesothelioma have been identified, giving a SIR of 26 per 100,000 [22]. The figure for Karain is about 15-times higher. These figures must be correlated with the average time spent at the villages; in Wittenoom, only $41 \%$ had an exposure of $\geq 2$ yrs. Even so, it seems that the risk of mesothelioma from erionite is at least 100times as high as is the risk from crocidolite. This illustrates the extraordinary capacity of erionite to cause mesothelioma.

In the present study, the male to female ratio of malignant pleural mesothelioma was 0.8 , which is different from the reports from various countries. This is of course due to the fact that mesothelioma in the industrialized societies is due mainly to occupational exposure to asbestos, which is most common among males. This shows that the exposure to erionite is environmental with the same exposure levels for both sexes.

The mean age of mesothelioma appearance, equalling the latency time, was $\sim 50$ yrs for both sexes in this series. The latency period in occupational exposure is generally 35-40 yrs, and consequently the mean ages of the patients is around $60-65$ yrs $[19,23,24]$. Thus, it seems that the latency time for mesothelioma caused by erionite is longer than those caused by asbestos; however, the lower mean latency time for asbestos-related mesothelioma might be 
due to the fact that these cohorts have not been followed long enough.

The mean age of mesothelioma appearance in the villagers who continue to live their lives in Karain is very similar to those in the present cohort, who actually left the village at a young age [1]. This means that cumulative total exposure (which of course is higher in those remaining) does not appear to cause a shorter latency time. However, from figure 2 one can see a tendency for increased risk with increased exposure: there was no mesothelioma in those exposed for $<10 \mathrm{yrs}, 3$ of 57 (5\%) exposed for 10-19 yrs, 5 of $48(10 \%)$ exposed for 20-29 yrs, 7 of $27(26 \%)$ exposed for 30-39 yrs and 3 of 7 (43\%) exposed for $>40$ yrs. The actual figures are low and care must be taken when interpreting them. However, these data are in accordance with the study from Wittenoom [22], where the risk was significantly related to the time spent at Wittenoom, in other words to an cumulative exposure.

\section{References}

1. Baris B, Demir AU, Shehu V, Karakoca Y, Kisacik G, Baris YI. Environmental fibrous zeolite (erionite) exposure and malignant tumors other than mesothelioma. $J$ Environ Path Tox Oncol 1996; 15: 183-189.

2. Baris YI, Simonato L, Artvinli M, Pooley F, Skidmore J, Wagner C. Epidemiological and environmental evidence of health effects of exposure to erionite fibers: a four year study in the Cappadocian region in Turkey. Int J Cancer 1987; 39: 10-17.

3. Poole A, Brown RC, Turwer CJ, Skidmore JW, Griffiths DM. In vitro genotoxic activities of fibrous erionite. $\mathrm{Br} \mathrm{J}$ Cancer 1983; 47: 697-705.

4. Wagner J, Skidmore JW, Hill RJ, Griffiths DM. Erionite exposure and mesothelioma in rats. Br J Cancer 1985; 51: 727-730.

5. Özesmi M, Patiroglu TE, Hillerdal G, Özesmi C. Peritoneal mesothelioma and malignant lymphoma in mice caused by fibrous zeolite. Br J Ind Med 1985; 42: 746749.

6. Suzuki Y, Koyama N. Malignant mesothelioma induced by asbestos and zeolite in the mouse peritoneal cavity. Environ Res 1984; 35: 277-292.

7. Boman G, Schubert V, Svane B, et al. Malignant mesothelioma in Turkish immigrants residing in Sweden. Scand J Work Environ Health 1982; 8: 108-112.

8. Özesmi M, Hillerdal G, Svane B, Widström O. Prospective clinical and radiological study of zeolite-exposed
Turkish immigrants in Sweden. Respiration 1990; 57: 325-328.

9. Hillerdal G. Pleural plaques and risk for bronchial carcinoma and mesothelioma: a prospective study. Chest 1994; 105: 144-150.

10. Berry M. Mesothelioma incidence and community asbestos exposure. Environ Res 1997; 75: 34-40.

11. Cancer Incidence in southern Sweden 1988-1992. Lund, Malmö, 1994.

12. The Official Cancer Registry for Sweden, 1994.

13. Baris E, Baris YI. Environmental exposure to fibrous zeolite in Turkey: an appraisal of the epidemiological and environmental evidence. In: Peters GA, Peters W, eds. Asbestos Risks and Medical Advances. Salem, NH, Butterworth Legal Publishers, 1993; pp. 53-72.

14. Saracci R, Simonato L, Baris YI, Artvinli M, Skidmore J. The age-mortality curve of endemic pleural mesothelioma in Karain, central Turkey. Br J Cancer 1982; 45: 147149.

15. Karakoca Y, Emri S, Cangir AK, Baris YI. Environmental pleural plaques due to asbestos and fibrous zeolite exposure in Turkey. Indoor Built Environ 1997; 6: 100-105.

16. Baris YI, Sahin AA, Özesmi M, et al. An outbreak of pleural mesothelioma and chronic fibrosing pleurisy in the village of Karain/Ürgüp in Anatolia. Thorax 1978; 33: 181-185.

17. Sebastien P, Gaudichet A, Bignon J, Baris YI. Zeolite bodies in human lungs from Turkey. Lab Invest 1981; 44: 420-425.

18. Maltoni C, Minardi F, Morisi L. Pleural mesotheliomas in Sprague-Dawley rats by erionite: first experimental evidence. Environ Res 1982; 29: 238-244.

19. Letourneux M, Galateau F, Legendre C, et al. Malignant mesotheliomas diagnosed in lower Normandy between 1980 and 1990. Eur Respir Rev 1993; 3: 87-88.

20. Armstrong BK, De Klerk NH, Musk AW, Hobbs MST. Mortality in miners and millers of crocidolite in Western Australia. Br J Ind Med 1988; 45: 5-13.

21. Rogers A, Nevill M. Occupational and environmental mesotheliomas due to crocidolite mining activities in Wittenoom, Western Australia. Scand J Work Environ Health 1995; 21: 259-264.

22. Hansen J, De Klerk NH, Musk AW, Hobbs MST. Environmental exposure to crocidolite and mesothelioma: exposure-response relationships. Am J Respir Crit Care Med 1998; 157: 69-75.

23. Walz R, Koch HK. Malignant pleural mesothelioma: some aspects of epidemiology, differential diagnosis and prognosis. Path Res Pract 1990; 186: 124-134.

24. Rusch VW. Diagnosis and treatment of pleural mesothelioma. Semin Surg Oncol 1990; 6: 279-285. 